Revista 2020

\title{
Huellas de un trauma psicosocial y retos pedagógicos para la construcción de paz en Colombia*
}

\author{
Sandra Milena Serrano Mora ${ }^{a}$ Marieta Quintero Mejía
}

Resumen: El artículo se propone documentar a partir de algunos episodios del conflicto armado colombiano, el impacto que ha tenido este en el tejido social, desde la configuración de lo que MartínBaró (1988) denominó trauma psicosocial. Este implica una afectación colectiva, específicamente en los lazos comunales, mediados por representaciones, lenguajes, prácticas y culturas que establecieron dinámicas relacionales basadas en la indiferencia, la prevención y la exclusión del otro. Para sustentar la idea de este trauma psicosocial se revisan dos momentos históricos, sin desconocer las huellas e impresiones de otros procesos como el de la conquista y la colonización, que también han sido documentados, pero que no se abordan aquí. El primer momento, denominado "la época de la Violencia", constituye un periodo en el que se instalaron algunas de las marcas que reflejan ese trauma psicosocial, tales como la lógica amigo/enemigo, un ethos social de odios heredados comunitariamente, un ambiente de tensión y prevención, el convencimiento de que la violencia es la única alternativa entre otras. El segundo, ubicado en la década del 80 y 90, viene atravesado por el narcotráfico con la participación de actores disímiles y letales que se conjugaron de diferentes maneras: guerrilla, paramilitares, narcotraficantes y clase política colombiana. Posteriormente, se abordan algunos retos pedagógicos para la construcción de paz, a partir de la etapa del posacuerdo. Una vez firmado el acuerdo de paz en el año 2016 entre el Gobierno nacional y las Fuerzas Armadas Revolucionarias (FARC-EP), el país aún vive situaciones de violencia política y social, en medio de expresiones de conflicto armado. Atendiendo a esta situación, se plantea la propuesta de una Terapéutica Social, recurriendo a dos fuentes, las voces de las víctimas y el arte como escenario de encuentro y de resignificación.

Palabras clave: conflicto; violencia; trauma psicosocial; terapéutica social; posacuerdo; construcción de paz

Recibido: 13 de enero de 2020. Aceptado: 11 de mayo de 2020.

Disponible en línea: 22 de octubre de 2020.

Cómo citar: Serrano Mora, S. M. y Quintero Mejía, M. (2020). Huellas de un trauma psicosocial y retos pedagógicos para la construcción de paz en Colombia. Academia y Virtualidad, 13(2), 19-34. https://doi.org/10.18359/ravi.4496

* Artículo de reflexión.

a Magíster en Desarrollo Educativo y Social. Profesora asociada Universidad de Santander, Bucaramanga, Colombia. Correo electrónico: sserrano@udes.edu.co. ORCID: http://orcid.org/0000-0002-5670-2699

b Doctora en Ciencias Sociales, Niñez y Juventud. Profesora Universidad Distrital Francisco José de Caldas, Bogotá, Colombia. Correo electrónico: marietaqmg@gmail.com. ORCID: https://orcid.org/0000-00028001-4511 


\title{
Traces of a psychosocial trauma and pedagogical challenges for peacebuilding in Colombia
}

\begin{abstract}
The article aims to document, based on some episodes of the Colombian armed conflict, the impact it has had on the social fabric, from the configuration of what Martín-Baró (1988) called psychosocial trauma. This implies a collective damage, specifically to the community ties, mediated by representations, languages, practices, and cultures that established relational dynamics based on indifference, prevention, and exclusion of the other. To support the idea of this psychosocial trauma two historical moments are analyzed, without ignoring the traces and impressions from other processes such as conquest and colonization, which have also been documented, but are not addressed herein. The first moment, called "the era of Violence", constitutes a period in which some of the marks that reflect this psychosocial trauma were incepted, such as the friend/foe logic, a social ethos of community-inherited hatreds, an environment of tension and prevention, the conviction that violence is the only alternative among others. The second one, corresponding to the $80 \mathrm{~s}$ and $90 \mathrm{~s}$, is marked by drug trafficking with the participation of dissimilar and lethal actors that were combined in different ways: guerrillas, paramilitaries, drug traffickers and the Colombian political class. Subsequently, some pedagogical challenges for peacebuilding are addressed, starting from the post-agreement stage. Once the peace agreement was signed between the National Government and the Revolutionary Armed Forces (FARC-EP) in 2016, the country still experiences situations of political and social violence, amid expressions of armed conflict. Taking into account this situation, the proposal of a Social Therapeutics is presented, resorting to two sources, the voices of the victims and art as a scene of encounter and resignification.
\end{abstract}

Keywords: conflict; violence; psychosocial trauma; social therapeutics; post-agreement; peacebuilding

\section{Marcas de um trauma psicossocial e desafios pedagógicos para a construção de paz na Colômbia}

Resumo: 0 artigo propõe documentar, a partir de alguns episódios do conflito armado colombiano, o impacto que este tem tido no tecido social, a partir da configuração do que Martín-Baró (1988) denominou trauma psicossocial. Este implica uma afetação coletiva, especificamente nos laços comunais, mediados por representações, linguagens, práticas e culturas que estabeleceram dinâmicas relacionais baseadas na indiferença, na prevenção e na exclusão do outro. Para sustentar a ideia desse trauma psicossocial, revisam-se dois momentos históricos, sem desconhecer as marcas e impressões de outros processos como o da conquista e da colonização, que também foram documentados, mas que não se abordam aqui. O primeiro momento, denominado "a época da Violência", constitui um período no qual se instalaram algumas das marcas que refletem esse trauma psicossocial, tais como a lógica amigo/inimigo, um ethos social de ódios herdados comunitariamente, um ambiente de tensão e prevenção, o convencimento de que a violência é a única alternativa entre outras. O segundo, localizado nas décadas de 80 e 90, vem atravessado pelo tráfico de drogas com a participação de atores dissimilares e letais que se conjugaram de diferentes maneiras: guerrilha, paramilitares, narcotraficantes e classe política colombiana. Posteriormente, abordam-se alguns desafios pedagógicos para a construção de paz, a partir da etapa do pós-acordo. Uma vez assinado o acordo de paz no ano de 2016 entre o Governo Nacional e as Forças Armadas Revolucionárias (farc-ep), o país ainda vive situações de violência política e social, no meio de expressões de conflito armado. Atendendo a essa situação, apresenta-se a proposta de uma Terapêutica Social, recorrendo a duas fontes, as vozes das vítimas e a arte como palco de encontro e de ressignificação.

Palavras-chave: conflito; violência; trauma psicossocial; terapêutica social; pós-acordo; construção de paz. 


\section{Introducción}

Tratar de comprender las dimesiones del daño causado no solo a las víctimas del conflicto armado colombiano, sino a todo el tejido social, implica revisar cuáles han sido las marcas que ha dejado la crueldad de la violencia de este conflicto, aquellas que superan los efectos psicológicos individuales y obligan a pensar en una afectación más colectiva y grupal.

Este artículo se centra en analizar estas heridas de la violencia, acudiendo a dos períodos ampliamente documentados acerca de la violencia en Colombia, sin desconocer por ello que esta historia de la violencia, en este territorio, prácticamente se ha gestado con los mismos procesos colonizadores que se vivieron hace 500 años. Así lo señala González-González (2014), al plantear esa noción de Estado que fue configurándose de manera arbitraria en tres dimensiones, la global, la nacional y la local, mediadas por pautas de interacción violentas, que datan desde la época colonial hasta la actualidad.

Reconociendo este aspecto fundante de la violencia, desde los procesos desarrollados en la naciente Nueva Granada, las tensiones regionales en los inicios de la República, la colonización campesina y los conflictos rurales (González-González, 2014), que demarcaron un horizonte si se quiere conflictivo desde los inicios, se retoman para efectos del análisis presentado dos momentos que se pueden asumir como consolidadores de esa cultura violenta, el primero surgido a partir del hito histórico, el asesinato de Jorge Eliecer Gaitán (1948), y el segundo la denominada época de la Violencia bipartidista (Vásquez, 2007).

Colombia sufrió el impacto de una dura prueba desde 1930, agudizada desde 1948 hasta mediados de la primera década del 2000, a la que, por sus características siniestras, se ha denominado "Violencia". Mucho se ha escrito sobre ella, pero no hay acuerdo en cuanto a las marcas sociales que esta ha impreso de manera casi imperceptible en todos los escenarios de la vida cotidiana y en las interacciones entre las personas, más allá de haber sido parte o no de manera directa en la ejecución de hechos violentos.
En suma, la afectación colectiva se puede resumir en una situación patológica generalizada, que Martín-Baró (1988) denominó trauma psicosocial, en la que se afectan todos los lazos comunales alterando las dinámicas cotidianas que median en una comunidad, territorio o región. La "Violencia", entonces, se convirtió en algo común a todos, les hizo legitimar prácticas o formas de pensar que parecían normales solo porque todos estaban inscritos en ellas.

Los diferentes ciclos de esta Violencia reafirmaron un ethos comunitario traumatizado, que no solo tiene expresiones individuales, expresadas en condiciones psicológicas de las víctimas, sino en marcas sociales profundas que dirigen el sentir y actuar en torno a esos "otros" que también hacen parte de las comunidades en donde se habita.

Es por ello que este artículo trata de evidenciar cómo en dos diferentes momentos de la Violencia en Colombia -la denominada primera época de la Violencia y la época de los $80 / 90^{1}$ - se fue configurando un trauma psicosocial, en el sentido que adopta y caracteriza Martín-Baró, para quien este constituye la cristalización concreta, en individuos, de relaciones sociales aberrantes y deshumanizantes (1988, p. 4).

Estas relaciones sociales deshumanizantes se fueron fraguando en la medida en que las violencias se hacían más intensas y crueles; producto de toda esta vivencia, la sociedad colombiana hoy se enfrenta a unos retos importantes, que le imponen la urgencia de transformar prácticas e interacciones que habían sido construidas desde la indiferencia y la desesperanza.

Para explicar este trauma psicosocial, consecuencia de una violencia prolongada, se hace un recorrido por la historia del conflicto armado, tratando de destacar aquellos momentos, situaciones y condiciones que contribuyeron a que se estructurara toda una forma de sentir y actuar colectiva que legitima ciertas posturas y desvirtúa otras, en

1 Los historiadores ubican diferentes momentos de la violencia o del conflicto interno colombiano. Para efectos del análisis que aquí se realiza se toman solo dos por considerarlos suficientes para sustentar lo que se quiere mostrar: 1) la primera, época de la violencia bipartidista y 2) la segunda, violencia de los 80/90 con guerrillas, narcotráfico y paramilitarismo (Melo, 2017). 
torno a la interacción con los demás, así como a las justificaciones y significados de la violencia en la sociedad.

Se parte de una tesis que parece una verdad a gritos, pero que no se ha analizado en profundidad: esto que nos pasó, nos pasó a todos, no a unos cuantos. Por ello se proponen los retos que supone para toda la sociedad una terapéutica social, en medio del momento coyuntural en el que el país se encuentra: el posacuerdo.

\section{El trauma psicosocial en la primera época de la violencia}

Desde la primera época de la Violencia, caracterizada por el enfrentamiento bipartidista, se instauró una marca polarizante en el tejido social, a partir de lo que Pécaut (2013) denominó la lógica amigo-enemigo, que se podría traducir en la vieja expresión popular "el que no está conmigo, está contra mí”.

Las luchas bipartidistas entre liberales y conservadores fueron el punto de partida para un enfrentamiento entre bandos o grupos que aun hoy se mantiene como el soporte de posturas radicales y polarizadas que no permiten aceptar la diferencia o actuar de manera empática hacia los demás. Como primera expresión de la afectación de esos lazos comunales, pertenecer a uno u otro grupo supone excluir, señalar o eliminar a quien no hace parte de este, a quien no comparte las mismas creencias o principios.

Es cierto que, en la naturaleza humana, desde una perspectiva sociológica, se encuentra la tendencia a pertenecer a un "nosotros", diferenciándose de un "ellos", tal como lo plantean Bauman y May, 2004, a propósito de lo argumentado:

Bauman parte, de nuevo, de premisas compartidas por los socirminos muy sencillos: or los sociy Social. Especialista en Docencia Universitaria. a la JEP.s iera que existo a 14 personas, enólogos y las lleva a términos muy sencillos: la manera en que sentimos nuestra pertenencia a un "nosotros" porque pensamos en otro grupo como "ellos". El lugar que ocupan los dos grupos, solo puede entenderse, a partir de su diferenciación mutua, de la línea divisoria que los separa, la cual debe ser vigilada constantemente (Bauman y May, 2004, citado por Castaño, 2004, p. 158).

También es cierto, con todo, el hecho del que, en el marco del conflicto armado, en esta época en particular, esta diferenciación estuvo marcada por aspectos políticos que desdibujaron esas líneas divisorias, desde los cuales estos límites solo podían ser resueltos con la violencia y con la muerte. No había forma de un "nosotros" y un "ellos" coexistiendo, solo era concebible una pertenencia a un grupo (liberal o conservador), como la única posible y verdadera. Esos otros, ellos, debían ser eliminados, borrados literalmente de la existencia física y territorial, como en efecto ocurrió.

En este primer momento de hostilidades entre liberales y conservadores en la historia de Colombia (1948-1958), las confrontaciones ocurrieron entre habitantes cercanos, amigos y vecinos que de un momento para otro se convirtieron en enemigos. Así lo plantea Ángela Uribe:

la guerra tuvo lugar por entonces entre vecinos. La distancia entre una y otra vereda no solía superar el par de kilometros y, sin embargo, los antagonismos más marcados entre liberales y conservadores surgieron entre quienes (de vereda en vereda, de hacienda en hacienda), se conocían; entre quienes hablaban el mismo idioma, compartían las mismas creencias religiosas, llevaban a sus hijos a la misma escuela, crecían en los mismos paisajes (2009, p. 163).

Este hecho, de por sí, ya es muy llamativo en el análisis que se está presentando, pues no solo se trató de un antagonismo entre amigos/enemigos (Pécaut, 2013), sino también de instalar una idea de poderío y sometimiento violento a las ideas que se profesaban, sin respetar o aceptar las de esos "otros" conocidos, generando una esprial de violencia que aún hoy se percibe en términos muy semejantes a como los describían Guzmán, Fals-Borda y Umaña, "producido el primer ataque sangriento de liberales contra conservadores o viceversa, el proceso se desarrollaría automáticamente, vendría entonces el deseo de venganza y quedaría urdida la cadena de la violencia, que después sería imposible de romper" (2010, p. 39).

También en esta época los victimarios acusaban a los del otro bando y los identificaban con 
sustantivos como "los pájaros" (usado por los liberales para reconocer a los asesinos a sueldo) o "los chulavitas" (la forma en que los liberales llamaban a la policía); por su parte los conservadores llamaban a los liberales "chusmeros" o "bandoleros". Todo esto hacía referencia a al otro desde una condición de pertenencia que lo alejaba de las sensibilidades humanas y lo cosificaba, para así poderlo aniquilar más fácilmente (Uribe, 2004).

Esta pertenencia a determinados grupos marcaba en gran medida las diferentes formas de violencia y ataques que se cometían a unos y otros, también la identificación y pertenencia colectivas, instaurando una división simbólica sin relación, o casi ninguna, con las divisiones sociales, con fronteras políticas, jerárquicas, que se han perpetuado hasta ahora (Pécaut, 2013). De manera que aún en la actualidad se evidencian criterios grupales que llevan a señalar, juzgar o justificar acciones de violencia, rechazo o exclusión frente a personas que se siguen ubicando, ya no entre azules o rojos (conservadores o liberales), sino como parte de un grupo determinado, por ejemplo ser víctima del conflicto armado, desmovilizado de grupos guerrilleros o paramilitares, o cualquier otra etiqueta que permita asumir o justificar las actitudes o acciones frente a ellos. Estas etiquetas, en las que incluimos a diferentes personas, suelen ser suficientes para juzgar la condición del otro, sus motivaciones o incluso su naturaleza dañada o desviada. Así lo afirman los análisis del CNMH (2015), respecto del análisis del desplazamiento forzado en Colombia:

En Colombia las víctimas de esta forma de violencia se han visto en la necesidad de hacer parte de un registro que les imprime el apellido que tendrán que llevar para acceder a la oferta de bienes y servicios: "desplazados". Apellido que es ahora un denominador común entre campesinos, indígenas, afrocolombianos, maestros, sindicalistas, alcaldes, ganaderos, estudiantes, líderes sociales, niños, abuelos. En muchas ocasiones ese apellido tiene un carácter estigmatizante, un estigma que supone una marca moral que identifica de forma negativa a las personas que lo han padecido, generando en algunos casos sentimientos de culpabilización por ser sobrevivientes de un conflicto armado, y en otros, son generadores de nuevas victimizaciones (p. 451).
En este sentido, se produce lo que Martín-Baró (1988) denominó "ethos comunitario", con relaciones sociales cifradas en odios heredados que instauraron formas de desconocimiento, deslegitimación y minimización del otro en su condición de ser humano, solo por el hecho de pertenecer a determinado grupo o actuar bajo ciertos cánones establecidos. Se recuerda al otro con odio, con sed de venganza, por hechos que ni siquiera le corresponden o le son dados en su persona, sino en el grupo al que pertenece.

Parte de lo que decide qué tan arraigado está el sentido comunitario en los miembros que representan una determinada cultura es, sin lugar a dudas, la minoría negativa; es decir, el hecho de que en nombre de aquello que encarna esa comunidad han muerto amigos o miembros de la familia que es preciso recordar. En el contexto histórico que nos ocupa, esto se ve reflejado en la situación de los campesinos de la región cafetera del occidente del Tolima colombiano, entre los años treinta y cincuenta del siglo XX; ellos nacían para recordar a los propios muertos, es decir, nacían liberales o nacían conservadores (Uribe, 2004, p. 58).

En esta primera época de la violencia, se encuentra también una "indiferencia colectiva" de parte de quienes no estaban asistiendo como testigos de primera mano ante los horrores y los actos de sevicia a los que eran sometidos unos y otros, dependiendo del grupo que atacara. Nada de lo que ocurría en el enfrentamiento entre liberales y conservadores, y posteriormente entre guerrilla, paramilitares, narcotráfico y demás actores involucrados provocaba alarma o solidaridad en las ciudades capitales del país, pues estos enfrentamientos ocurrían lejos de los centros urbanos, principalmente en la amplia zona rural del país:

ni los conservadores asesinados por los liberales, ni los liberales asesinados por los conservadores provocan nuestra alarma o nuestra indignación, porque todos esos informes son recibidos con un considerable descuento inicial. Esperemos dicen las gentes, a ver cómo pasaron las cosas. Y ese -como pasaron las cosas- no se sabe jamás (Guzmán, Fals-Borda y Umaña, 2010, p. 42). 
Siguiendo a Sontag (2013), podemos decir que los colombianos se acostumbraron, se silenciaron y buscaron formas racionales para justificar los daños ocasionados a las víctimas; se llegó incluso a justificar la violencia a partir de la idea común de que cada quien se busca o merece lo que le ocurre.

Esta indiferencia colectiva es una muestra de un trauma psicosocial, en tanto se trata de condiciones sociales que no solo produjeron la violencia, sino que la han mantenido hasta el día de hoy promoviendo un rol pasivo en aquellos que han sido testigos distantes de esa violencia, un rol que los incapacita para percatarse de lo que ocurre a su alrededor, para "ver al otro", para vincularse y ayudar desde la convivencia y la acción conjunta, en pro del bienestar común.

Es así como el conjunto de características del trauma psicosocial, que se logra rastrear en esta primera época de la violencia, responde a la percepción colectiva de un ambiente de tensión, desconfianza e inseguridad social al que paradójicamente parece que la gente se acostumbró.

De tal manera, cuatro o cinco generaciones de colombianos no conocieron un entorno distinto al ambiente enrarecido, precavido y tensionante de la violencia, en el que cada individuo se replegaba sobre sí mismo, se protegía o protegía a sus familiares y, para ello, tenía que realizar sus actividades cotidianas aún en medio de los estragos de esta. Además de enfrentarse, directa o indirectamente, a ambientes políticamente tensionantes, que de vez en cuando eran agudizados por expresiones de resistencia, protesta e insatisfacción, protagonizadas por diferentes organizaciones gremiales o no gubernamentales en el país:

los días discurren bajo una gran tensión política y social con marcada tendencia a la anarquía, reflejada en una creciente ola de huelgas y paros solidarios que se extienden por todo el país desde el mes de septiembre de 1946 (Guzmán, Fals-Borda y Umaña, 2010, p. 43).

Es así como a partir de esta primera época de la violencia se aceptó socialmente la idea de convivir en medio de la desconfianza, del peligro inminente y de las posibles señales de violencia: "según Francisco Gutiérrez, el conflicto destruyó de manera masiva tejido social, tradiciones positivas y redes de confianza (...) (y) tuvo un efecto deletéreo sobre la confianza de los colombianos en sus conciudadanos y en las instituciones" (Pizarro León-Gómez, en Comisión para el Esclarecimiento Histórico sobre el Conflicto y sus Víctimas [en adelante CHCV], 2015, p. 91).

\section{La violencia de los años 80 y 90: cristalización del trauma psicosocial}

Ya en este momento de la violencia, entretejido por diferentes situaciones y actores, mucho más letales y contundentes, entre ellos guerrillas, paramilitares, narcotráfico, incluídas alianzas fatales entre fuerzas del Estado y estos grupos, que si bien se habían dado en otros momentos de la violencia, en este particular fueron decisivas para el ambiente de caos instalado, se reafirmó aún más una percepción colectiva de desasasoiego, en especial porque estaban directamente involucradas las instituciones, cuando se supone que los gobiernos están para garantizar la legalidad y esa institucionalidad que representan:

los carteles de la droga produjeron profundos cambios en la estructura de la sociedad colombiana al ejercer una honda influencia en la política mediante una combinación de amenazas, corrupción y violencia, que les abrió un lugar prominente en los gobiernos locales e incluso, en el nivel nacional ( $\mathrm{CHCV}$, 2015, p. 59).

También se afirma, en la CHCV (2015), cómo el secuestro y la extorsión constituyeron patrones de violencia contra civiles, que sirvieron a los grupos guerrilleros para fines económicos y también sirvieron de motivo para la organización de grupos paramilitares, que surgieron con la idea de contrarrestar, a cualquier precio, estas acciones:

el crecimiento exponencial del secuestro y la extorsión en los años ochenta y noventa del siglo pasado fueron, en un doble sentido, otros dos importantes "combustibles" del conflicto armado. De un lado, sirvieron de fuente financiera para la rápida expansión de los grupos guerrilleros, que multiplicaron sus ingresos y, por tanto, su capacidad de reclutamiento. 
Pero, de otro lado, desataron la reacción de las víctimas, lo cual sirvió de acicate para la formación del paramilitarismo (p. 63).

Esta misma Comisión menciona la participación de agentes en el fenómeno paramilitar, tan marcadamente violento, en diferentes regiones del país y los agentes que se combinaron para crearlo y justificar sus acciones:

el auge de los grupos paramilitares se sostuvo gracias al apoyo de cuatro tipos de agentes: (a) la insubordinación de élites rurales legales, que se sentían desprotegidas por parte del Estado frente al secuestro y la extorsión; (b) el protagonismo de élites ilegales, en especial las mafias de las drogas ilícitas; (c) la participación de amplios sectores de la clase política y (d) la participación de miembros de las agencias de seguridad del Estado (p. 69).

Producto de estos procesos que se vivieron con distintas intensidades, a lo largo y ancho del país, el trauma psicosocial continuó delimitando esas interacciones sociales en los pueblos, las veredas, los municipios e incluso en las grandes ciudades. Se aceptó el poder coercitivo, establecido desde las armas, el falso orden establecido por medio de la violencia esgrimida por los diferentes bloques de paramilitares en territorios alejados de las capitales.

Fue así como, en esta época en particular, el trauma psicosocial se hizo más evidente, en especial, porque impidió concebir formas de relación distintas a las de la violencia o el miedo producida por esta, al establecer una escisión social que hasta el día de hoy marca los lenguajes, las actuaciones $\mathrm{y}$ las percepciones que se tienen frente a los cercanos (familiar, vecino, compañero de trabajo), pero también frente a los lejanos (ciudadanos, víctimas, administradores públicos).

Esta afectación de lazos comunales cimentados en la cotidianidad de la vida en el campo, en los barrios o en las ciudades, llegó por cuenta de los horrores de la violencia sin tregua, que expuso a las víctimas, de manera directa, y al resto de la sociedad, de manera indirecta, ante un escenario de crueldad y miedo, particularmente doloroso y desgarrador, por las acciones violentas de las que fueron objeto.
Por cuenta de esta crueldad, los lazos comunales se instauraron a partir del aniquilamiento del otro, la despersonalización de todo lo que en él pueda representar humanidad, y por tanto obligue a reconocerle como alguien igual al otro. En palabras de Uribe (2009), se trata de despojar al otro de su condición humana, de bestializarlo, y de esta manera no sentir ningún dolor o culpa al agredirlo, al victimizarlo y posteriormente al excluirlo, señalarlo o juzgarlo.

Esto aparece con mayor fuerza en las narraciones de la violencia de esta década, de los 80 y los 90 , con el auge del narcotráfico y del paramilitarismo. Pero también, esa crueldad no solo tiene la intención del aniquilamiento de la condición humana en algún individuo particular, sino en un "otro" social que se ve reflejado no en la persona de la víctima sino en un grupo, una comunidad. En el desprecio por todo lo que ella representa y el aniquilamiento de sus condiciones socio-culturales, sus creencias, su identidad,

todos los grupos armados han justificado estos crímenes señalando a los civiles como prolongación del enemigo. 'Pueblo guerrillero', 'pueblo paraco', 'guerrillero de civil' son algunas de las frases con las que justifican sus incursiones y acciones violentas y con las que estigmatizan a la gente (Centro Nacional de Memoria Histórica [CNMH], 2013, p. 25).

Es así como se sigue fortaleciendo la idea de que el otro es un enemigo, ya no enfocado solo en la particularidad del sujeto, sino todo lo que representa; ese enemigo, entonces, ya no es un individuo, es una comunidad, un pueblo, al que se le señala y se le juzga en nombre de una causa o de una lucha. Así lo reflejan las narraciones de la violencia, en las que se puede leer entre líneas cómo esta logró configurar el trauma psicosocial, reflejado en el menoscavo de condiciones valorativas, incluso de las más abstractas y constituyentes de la identidad comunitaria.

Muchos actos violentos han buscado menoscabar los valores de las comunidades y las personas, degradar su dignidad, devaluar sus ideales y creencias, y socavar los pilares de la identidad colectiva. Las comunidades narran con dolor e indignación la forma en que los actores armados, y las élites que 
los respaldaron, expresaron desprecio hacia sus prácticas religiosas y culturales, sus características fenotípicas o étnicas, y sus convicciones políticas. En algunos casos esto fue experimentado como sacrilegio (CNMH, 2013, p. 64).

Ese desprecio hacia el otro, hacia el grupo que representa (estrato, etnia, cultura, condición social), hace parte de la afectación a los lazos comunales hasta la actualidad. Adicionalmente, los actos crueles y deshumanizantes a los que fueron sometidas las víctimas, expresados en masacres, atentados o violaciones sexuales, también cumplieron un cometido, el de imprimir un mensaje que fue leído e interpretado por comunidades enteras (cercanas y lejanas). Ese mensaje se instaló en los lenguajes cotidianos, estableciendo así una especie de "ceguera social": no enterarse, no saber, no comprometerse es una garantía para sobrevivir.

Ahora bien, el miedo promovido por las acciones de los diferentes actores violentos (guerrilla, paramilitares, delincuencia común, incluso los organismos del estado como Policía o Ejército), además de sembrar incertidumbre y garantizar el completo control en extensos territorios, tuvo una función determinante en la afectación de esos lazos comunales, pues paralizó, silenció y anestesió a la sociedad en general, nadie quiere hablar o abogar por otros, la consigna es protegerse, salvarse de manera individual.

Hubo asesinatos que buscaban infundir un terror más generalizado y desestabilizar el país, como ocurrió con los magnicidios que se cometieron para generar la sensación de desamparo y desgobierno. La muerte de Jaime Garzón, monseñor Isaías Duarte Cancino, los profesores Hernán Henao, Alfredo Correa de Andreis, o Jesús Bejarano, constriñeron la capacidad de debate público, la libertad de expresión y pensamiento. En número, los líderes políticos parecieran no ser demasiados, pero en términos del daño a la democracia, es muy alto. Sus muertes o desplazamiento han debilitado las posibilidades de consolidar alternativas políticas en las regiones y se debilitó la participación, incluso en mecanismos democráticos como las elecciones (CNMH, 2013, p. 36).

En otras palabras, la instauración del miedo no solo cumplía el objetivo de poder y dominio en comunidades y territorios enteros, sino que se encargó de menoscabar lazos comunales y la percepción de seguridad y confianza, una clara secuela de esa afectación colectiva que se puede visualizar hoy en día en las formas de interacción basadas en la desconfianza, la prevención frente al otro. Así lo propuso Pécaut (2013), cuando se refirió a que el terror inducía de manera progresiva efectos de fragilización de los territorios, hacía estallar los referentes temporales y ponía en peligro la posibilidad de los sujetos para afirmarse en medio de referentes contradictorios (p. 121).

De esta forma, la historia del conflicto armado colombiano, en sus diferentes momentos, expresiones y actores, logró inscribir en la noción comunitaria una suerte de indiferencia social, quizá el mejor ejemplo de la afectación colectiva de la que hablaba Martín-Baró (1988), en tanto provocó una especie de fractura social (expresión del trauma psicosocial), en la que una parte de la sociedad (la mayoría), no se entera de lo que ocurre a su alrededor, se ocupa de sus intereses y objetivos propios, desconoce al otro que sufre, y otra parte (la minoría, las víctimas, sus familias y algunos líderes sociales) tratan de no dejar olvidar lo sucedido: "se trata, pues, de una triple imposibilidad la que quisiera resaltar en el contexto de la guerra que hace estragos en este momento: la imposibilidad de la memoria, la imposibilidad del olvido y la imposibilidad de la historia" (Pécaut, 2013, p. 177).

Además de esa indiferencia -acentuada a través del conflicto armado-, la desesperanza también hace parte de este trauma psicosocial, no hay confianza en que se pueda tener un futuro distinto, en que la violencia acabe o en que las instituciones del Estado tengan la suficiente capacidad para garantizar la seguridad y la confianza:

ante cada acontecimiento de resonancia como el asesinato de una personalidad, un acto territorista de envergadura o una masacre de dimensión desacostumbrada, la opinión reacciona como si la violencia acabara de tomar otro giro. Se podría hablar de una percepción caleidoscópica, como expresión de la dificultad de aprehender los fenónemos de la violencia en sus relaciones recíprocas (Pécaut, 2013, p. 14) 
También, esa desesperanza se cimentó en los territorios, en aquellos asesinatos anónimos para la sociedad en general, pero particulares, cercanos y familiares para quienes les conocían y les seguían.

Esas muertes, destierros, secuestros, amenazas o desapariciones estaban hechas para golpear la organización de la gente, debilitar su autonomía respecto a la guerra o a los actores dominantes en una región. También eran una manera de acabar con los valores simbólicos y el tejido social. El asesinato del maestro, la enfermera, el conductor, el lanchero, el tendero, causó un golpe duro a las comunidades, que los consideraban personas claves para el desarrollo. Los líderes comunales, sindicales o campesinos, periodistas, sacerdotes, dejaron también un vacío difícil de llenar porque significaban años de formación y tradición de lucha por el desarrollo social (CNMH, 2013, p. 36).

Aniquilando actores sociales comunitarios significativos para las personas, se aniquilaba la esperanza de un cambio o la perspectiva del compromiso frente a la lucha por el bienestar común. Fueron asesinatos anónimos para el país, pero con nombre propio, identidad y significado para quienes vivían e interactúaban con ellos.

Hoy, 70 años después de una vida social violenta, si tomamos en cuenta los dos períodos cronológicos señalados en los apartados anteriores, todo lo que ocurrió, las desapariciones, las masacres, las torturas siguen siendo temas ajenos a las preocupaciones cotidianas del grueso de la sociedad. Muchos hechos que dejaron marcas imborrables en personas, familias y comunidades siguen siendo invisibles²:

Mapiripán, El Salado, Segovia, Naya, Honduras, La Chinita y La Rochela son algunos de los nombres que están grabados en la memoria de los colombianos

2 Vale la pena aquí mencionar el trabajo del Centro de Memoria Histórica, frente a la recuperación de la memoria de lo vivido, así como el agenciamiento de organizaciones no gubernamentales de víctimas, que también han trabajado en el país por recuperar la memoria del conflicto, y el actual ejercicio de la Comisión de la Verdad en el marco del Sistema integral de Verdad, Justicia, Reparación y no repetición, producto del acuerdo de paz firmado en el año 2016 entre el Gobierno Nacional y las Fuerzas Armadas Revolucionarias -FARC-EP. por las grandes matanzas que allí ocurrieron. Estas expediciones nefastas llenaron los titulares de prensa y horrorizaron al país y al mundo por los métodos crueles empleados y por el alto número de víctimas que generaron. Sin embargo, la gran mayoría de las masacres (75\%) que el Grupo de Memoria Histórica logró documentar tuvieron cuatro, cinco o seis víctimas, y quedaron en el anonimato. Al ser frecuentes y menos espectaculares fueron rápidamente olvidadas, pues no tuvieron el despliegue mediático de las otras (CNMH, 2013, p. 28).

Se ha planteado durante todo el texto cómo la vivencia de un largo conflicto afectó de manera significativa los lazos comunales; se podría afirmar que la mayor expresión de ese trauma psicosocial colombiano, después de duras épocas de violencia, se cimenta en estos dos elementos: la indiferencia y la desesperanza. Estos son quizá los dos bastiones que se deben transformar (en la perspectiva de la etapa de posacuerdo que vive el país), para que ese barco no se hunda.

Aceptada esta premisa, alrededor de la cual se puede decir que, como producto de este trauma psicosocial instaurado en lo más profundo del tejido social, se han menoscabado las capacidades sociales para entretejer otras formas de interacción y se han instaurado prácticas de indiferencia, insensibilidad y apatía, la siguiente pregunta es ¿cómo podremos superar esta condición social en el marco del posacuerdo que actualmente vivimos? ¿Cómo garantizamos esas transformaciones también profundas en esos "lazos sociales" tan debilitados por la indiferencia y la deseperanza?

\section{Terapéutica social en el posacuerdo: un largo camino por recorrer}

Se podría afirmar que, a pesar de tanta violencia, el país empezó a hacer intentos por aplacar el sonido de las balas y permitir que otros espacios de diálogo y concertación surgieran, aun en medio de un ambiente de desconfianza y desesperanza, que dificulta concebir condiciones de convivencia e interacción, diferentes a las que la violencia comunicó e instaló. 
Los intentos que contribuyeron a que actualmente se pueda plantear, este asunto de una terapéutica social, se documentan, a través de los diferentes acuerdos establecidos con grupos al margen de la ley.

Un paso decisivo que abrió este camino, en el que hoy el país se encuentra, fue el reconocimiento, legal y social, de las víctimas, avalado por la ley 1448 de 2011. Esta, llevó a pensar en los daños ocasionados no solo a las personas, sino a las familias y comunidades, y en las diferentes formas de tramitar esos procesos de perdón, reconciliación y reparación. Así lo declaró el entonces presidente de la República de Colombia, el 10 de junio de 2011:

Si hemos tenido víctimas, si aún siguen produciéndose víctimas, vamos a ubicarnos y a pararnos en la orilla que nos corresponde: al lado de ellas, de su parte, abrazando y comprendiendo su sufrimiento (Santos, 2019, p. 256).

Este ambiente propicio también fue dado por acuerdos decisivos con grupos al margen de la ley, los dos más significativos, no solo por el número de desmovilizados sino por sus carácterísticas de violencia y daño a la población civil, fueron el acuerdo de Santafé de Ralito (2003), con el cual se logró la desarticulación de buena parte de los grupos paramilitares del país, y el acuerdo para la terminación definitiva del conflicto con las Fuerzas Armadas Revolucionarios - FARC-EP - (2016).

En datos concretos, se plantea una situación actual en la que confluyen más de ocho millones novecientas setenta mil víctimas (8.970.000), según el Registro Único de Víctimas (RUV)ª , algo más de 12.000 jóvenes paramilitares desmovilizados y en proceso de reincoporación a la sociedad, según la Agencia Colombiana para la Reincorporación y la Normalización (ARN), y cerca de 7.000 jóvenes integrantes de las FARC-EP, que dejaron las armas en el año 2017 según la Fundación Paz y Reconciliacion (2019) y se convirtieron en un movimiento político que pretende usar las vías democráticas

3 El RUv es un organismo adscrito a la Unidad para la Atención y Reparación Integral a las Víctimas de la Presidencia de la República. Tiene a su cargo el registro oficial de las víctimas del conflicto armado colombiano, a partir del año 1985, según lo estableció la Ley de Víctimas de 2011. para continuar trabajando por sus ideales. Además de una sociedad colombiana enfrentada a esos temas, estos rostros y estas historias, que ya no pasan tan desapercibidas y que, en su conjunto, reclaman que, por primera vez, en muchos años de violencias, se plantee la necesidad de una terapéutica social:

Colombia apenas comienza a esclarecer las dimensiones de su propia tragedia. La mayoría de sus ciudadanos aún no tiene una conciencia clara de los alcances que ha tenido la guerra interna, de sus impactos y sus mecanismos de reproducción. Muchos colombianos quieren seguir viendo en la violencia actual una simple expresión delincuencial o de bandolerismo, y no una manifestación de problemas de fondo en la configuración de nuestro orden político y social (CNMH, 2013, p.18).

En este sentido, es imperativo generar alternativas para transformar esas dinámicas de interacción basadas en la indiferencia, el miedo o la exclusión. Esto implica recurrir a diferentes voces, desde diversos sectores de la academia y de la sociedad civil, para pensar el tejido social, para ello también es necesario recurrir a procesos de memoria colectiva, de encuentros e intercambios de experiencias que nos permitan conocer procesos de reconstrucción y resignificación que han vivido las comunidades más golpeadas por las distintas violencias y desde ahí comprender vivencial y conceptualmente como transformar el dolor, de la desconfianza y la deshumanización que se instalaron como formas de interacción. En palabras de los investigadores del Centro de Memoria Histórica: "para cambiar duraderamente este escenario de tolerancias y complicidades con la guerra es menester una reconversión social, una inmensa tarea de pedagogía política, que revalore el disenso, la controversia, la diferencia" (CNMH, 2013, p. 14).

Además de lo anteriormente expuesto, la terapéutica social también implica asegurar condiciones de justicia, verdad y reparación, pero lo que se quiere proponer aquí es que esta terapéutica va más allá de esto, tiene que ver con procesos de reconciliación, perdón, reconocimiento del otro, superación de las desconfianzas y la desesperanza en las 
formas de comunicarse y de actuar con otros, lo que lleva a la necesidad de buscar alternativas para generar procesos de transformación de esas tramas relacionales en los microsistemas, con un eje transversal, los derechos humanos: "es preciso que las relaciones de los ciudadanos entre sí, y de estos con el Estado, tengan como un mínimo común el ejercicio y protección efectiva de los derechos humanos. Ese sería el fundamento normativo sólido de una reconciliación" (CNMH, 2013, p.15).

El camino por recorrer es mucho más complejo de lo que se alcanza a dimensionar, la participación de la sociedad en general, sobre todo aquella que no parece hacer parte de nada, es fundamental para que se puedan re-encontrar alternativas de perdón, reconciliación, superación del dolor, reconstrucción de la memoria y para la significación de relaciones sociales basadas en el respeto, la aceptación, la tolerancia, el reconocimiento del otro; todo lo contrario de lo que la violencia nos ha marcado en nuestra forma de pensar y actuar.

La complejidad de esta tarea se acentúa si se tiene en cuenta que, en este momento coyuntural que vive Colombia, no solo se están dando, quizá a la fuerza, estos procesos de construcción de paz, sino también co-existen las expresiones de violencia por parte de grupos armados disidentes de los acuerdos mencionados o de otros que aún mantienen la lucha armada como única posibilidad de transformación y cambio. También, porque el país se niega a reconocer las voces de líderes sociales, es por esto, que continúa asesinándolos, sin que haya procesos de judicialización claros al respecto. De acuerdo con Indepaz (2019), entre 2016 y 2019 fueron asesinados 837 líderes sociales.

No se podría esperar a una situación de completa paz o ausencia total de conflicto, en particular, porque se trata de un país con problemas estructurales como la desiguladad o la pobreza, situaciones que dificultan un estado ideal para pensar esta terapéutica social. La propuesta aquí es que, en medio de la violencia que aún se vive, sin las condiciones totalmente dadas, el país tiene que transitar hacia otras formas de relacionarse y de construirse como sociedad. Esta es una tarea que puede llevar generaciones pero que requiere empezar a realizarse.
En esta tarea, dos componentes pueden aportar significativamente: las voces de las víctimas y las diferentes expresiones artísticas o socio-culturales como posibilidad de reconfiguración social.

\section{Voces de las víctimas: exigencia para el posacuerdo}

Al reconocer las voces de las víctimas, se expresa la necesidad de comprender, desde su propia vivencia y experiencia, aquellos sentidos y significados que la violencia ha tenido, pero también las formas en que han tramitado el sufrimiento, se han organidado y apoyado con otras víctimas. También se plantea la posibilidad de aprender de sus experiencias cómo han encontrado formas para seguir adelante, aún en medio del dolor de la pérdida y de no poder reparar lo irreparable (Guzmán, 2012).

Estas voces, desde distintos lugares, han enseñado los caminos por donde transitar en esta terapéutica; han sido la expresión de quienes, desde la intuición, la fortaleza interna y la incidencia política, han mostrado que es posible no solo reponerse de manera personal sino comunitariamente, ante el daño causado.

Si bien el perdón y la reconciliación política no pueden deshacerse del pasado sobre todo por el daño moral y el sufrimiento causado por otros. Las victimas individuales y las comunidades políticas tienen el poder de redimir y liberar a los ofensores del daño moral y político que estos han causado. Solo se logra este proceso de reconciliación política, cuando el proceso posibilita una trasformación personal y política en los miembros de la comunidad. Esto quiere decir que las personas tienen que llegar a respetarse mutuamente como ciudadanos (Duque, 2014, p. 11).

Pero estas voces necesitan ser oidas sin reservas, sin prejuicios ni señalamientos; las organizaciones nacidas de las víctimas, de su dolor, han emprendido tareas de reconstrucción del tejido social que necesitamos reconocer, aprender de ellas los elementos que podamos trabajar en todas las comunidades. Su centralidad es fundamental para este proceso de reconfiguración, de superación del trauma psicosocial que se explicó anteriormente. 
De acuerdo con Todorov (2000, citado por Duque, 2014), se requiere sacar los relatos de las víctimas de su hábitat natural, de la esfera privada y doméstica. No se trata solamente del derecho de las víctimas a decir la verdad, sino del derecho de las sociedades a buscarla cuando se vive en un sistema democrático.

De manera que un rasgo fundamental de esta terapéutica social es el ser escuchado, escuchar al otro y sus razones, lo que contribuye a relativizar el propio sufrimiento, a encontrarle sentido en un contexto social y político determinado, y así desvirtuar la venganza. Realizar un ajuste de cuentas con el pasado se convierte en la cura contra el olvido; para ello, se debe reconstruir una historia colectiva cuyo hilo argumental convoque los diversos matices facilitando, así mismo, un discurso efectivo para promover la reparación y la justicia (Duque, 2014).

El tema de la memoria también es fundamental en la terapéutica, porque según Beristain, (2000, citado por Duque, 2014):

(a) permite reconocer social e individualmente la existencia y la realidad de los hechos. La persona y la comunidad pueden afirmar: "esto sí sucedió", no se puede desmentir. Con esto se rompe con la lógica de la impunidad y de "normalización de la violencia”, se abre el espacio para que sea inaceptable cualquier acción que atente contra la vida y la dignidad de la gente.

(b) logra mantener el hilo del pasado con el futuro, a través de la narración de los hechos en el presente. La violencia ha sido parte de la historia de este pueblo, pero no su único referente.

(c) propicia un proceso catártico personal y colectivo, donde se reintegra la experiencia en la historia vital y social que permite ir desalojando el dolor.

(d) abre espacio para la dignificación de las personas y las comunidades, puesto que abre oportunidades para que se pueda dar una reparación social. Es un paso hacia la verdad, la justicia y la reparación.

(e) reconstruye la identidad social e individual, puesto que a través de la memoria se genera cohesión y se fortalece el tejido social. El síntoma individual no se mira como patología, sino como una palabra no dicha, que encuentra su espacio social para expresarse, ser reconocida, con lo que se alivian también los malestares personales.

(f) finalmente, abre el espacio para la reflexión de tal manera que se puede pensar que los hechos no deben repetirse nuevamente, con lo cual también se deja un mensaje a las futuras generaciones, un aprendizaje social que fortalece los procesos de reconstrucción.

Y no hay mejor forma de transmitir esos mensajes, sino a través del arte, como escenario multifacético de expresiones y posibilidades.

\section{Expresiones artísticas y socio- culturales, como posibilidad de reconfiguración social}

Una de las cosas que se le reconoce a un país como Colombia es su amplia diversidad, heterogenidad, recursividad y creatividad, expresada en miles de expresiones musicales, teatrales, simbólicas o artesanales ancladas a la sabiduría de sus regiones, a la historia y herencia ancestrales.

Es por esto que, a la hora de encontrar estrategias para tramitar el dolor, el sufrimiento y las pérdidas humanas, afectivas y simbólicas, las organizaciones de víctimas, en particular, han utilizado estos recursos artísticos y socio-culturales que les han permitido no solo nombrar lo vivido sino también tratar de resignificarlo, desde otros lugares de comprensión.

Son muchos los ejemplos que frente a esto se pueden encontrar, por ejemplo, con la Organización Femenina Popular (2013), en la ciudad de Barrancabermeja (Santander), o con las Tejedoras de Mampuján en Montes de María. También con las organizaciones de víctimas, en el Chocó, Cauca o la Guajira (Rodríguez y Gaviria, 2014).

Una terapéutica social tiene que estar inspirada por la imaginación, por lo posible y lo indecible, todo ello susceptible de traducir en expresiones concretas a partir de las expresiones artísticas o 
socio-culturales, que connotan esas otras nociones subjetivas de recordar, de reparar, de perdonar.

Se trata, además, de combinar los ejercicios de memoria de las iniciativas artísticas locales con los recursos teóricos y metodológicos de disciplinas como la psicología, la sociología o la educación en interacción con los recursos socio-culturales instalados en la memoria colectiva de las comunidades y pueblos que han sufrido de manera directa los efectos de un largo y violento conflicto. Es ahí donde se encuentra la verdadera caja de herramientas psicosociales que permitan a las personas, las familias y las comunidades, utilizar estrategias que van más allá de lo conceptual y se ubican en lo simbólico, lo representativo, lo cultural y desde ahí permiten entretejer o recomponer esto que se ha denominado el tejido social.

Una terapéutica social no se lleva a cabo en los consultorios psicólogicos, aunque a veces se requieran también, se realiza en las comunidades, con sus propios recursos artísticos, culturales y simbólicos:

el arte entendido como un campo ofrece lugares de conexión y de encuentro donde cada persona puede pensarse como parte de un colectivo y asumir el sentido de su existencia. De manera que, si propiciamos espacios para reconfigurar lo sensible desde el pensamiento creativo, apropiando la pluralidad cultural y estética que caracteriza a Colombia, intensificaremos la relación entre lo urbano y lo rural y ampliaremos las posibilidades de lo local (Gil, 2010, citado por Bocanegra, 2015).

Algunas iniciativas de colectivos culturales y artísticos en el país se han ocupado de pensar los temas de la reconciliación y el perdón, a través de puestas en escena, de performance, instalaciones, actos simbólicos, en donde es posible utilizar el arte como vehículo de expresión, de sanación y de transformación.

La propuesta es sistematizar estas experiencias, para aprender desde ellas y así delinear una terapéutica social, que de maneras espontáneas ya se empezó a realizar en los territorios, en las familias y las comunidades de este país.

A través de diversas prácticas artísticas y culturales se le puede otorgar sentidos distintos a lo cotidiano y a las formas de relacionarse. También se puede vivenciar la diversidad, el respeto por las diferencias y comprender que cada persona desde su condición puede aportar al desarrollo humano (Bocanegra, 2015, p. 139).

En otras palabras, esta etapa de posacuerdo, en medio de expresiones de violencia que se mantienen, es una oportunidad valiosa para que en conjunto, como sociedad, se puedan transformar esas trazas de un trauma psicosocial históricamente construido, a partir de los componentes de una terapéutica social que involucra a todos y que los convoca en torno al establecimiento de nuevas pautas de convivencia, al reconocimiento del otro, la aceptación de la diferencia y la superación de una mirada violenta hacia la construcción de paz.

\section{Algunas reflexiones finales}

Dos aspectos finales son importantes para cerrar o mejor, dejar abierta esta discusión, acerca de una terapéutica social. La primera es que el país se enfrenta, por primera vez en la historia de estas violencias, a procesos de conversación sobre eso que ha pasado, los actores involucrados, los responsables, pero, sobre todo, se enfrenta a la posibilidad de realizar una mirada de presente, pasado y futuro. No es la primera vez, en estricto sentido, pues ya se habían tenido dos oportunidades de aproximación comprensiva al fenómeno de la violencia, con las comisiones investigadoras del $58 \mathrm{y}$ del 87 , las cuales contribuyeron en su momento y fueron el escenario previo para lo que hoy el país vive (Jaramillo, 2011).

Sin embargo, tal como lo plantea uno de los sociólogos que participó en estas comisiones:

el otro tema pendiente, muy grande por cierto, de este proceso, es el del impacto psicológico tanto para las comunidades como para el equipo de trabajo. Aquí se están "removiendo" unas heridas tan profundas para las cuales no estábamos preparados. Eso nos diferencia de otras comisiones en el país. No estaba preparada la academia, no estaba preparado el Estado, no estábamos preparados nosotros. En la comisión del 87, nosotros hablamos sentados desde los escritorios. Incluso, en los años cincuenta me imagino que se removieron muchas cosas, pero no 
había todavía una conciencia pública, ni institucional, ni internacional de lo que la guerra significaba (Jaramillo, 2011, p. 164).

Es decir que el escenario social, aún violento, confuso y enrarecido, nos está convocando a los académicos, investigadores y ciudadanos de este país, a enfrentarnos a lo sucedido, para no solo describir, como se ha hecho aquí, las huellas de un trauma psicosocial configurado a lo largo de la historia del conflicto armado colombiano, en solo dos momentos de esa violencia analizados, sino para construir de manera conjunta, y quizá también pausada, esto que se ha denominado una terapéutica social, que pasa por reconocer los saberes y prácticas socio-culturales que han surgido en medio del dolor, el sufrimiento y las perdidas.

Esta tarea también implica reconocer esas experiencias gestadas en la sabiduría popular, en las iniciativas culturales ancladas a las cosmovisiones de las comunidades, acerca de la vida, la muerte, el dolor, la alegría, la felicidad.

Es necesario reconocer todas esas iniciativas socio-culturales que las personas, las familias y las comunidades han ido construyendo, a la par con la violencia, desde sus propias comprensiones, desde su sentir y sus recursos locales, artísticos, experienciales. Porque como las víctimas mismas lo afirman, son víctimas, pero no por siempre (Equipo Verdad Abierta, Izaguirre y Rebollo 2016).

Quizá sea interesante pensar que no hay fórmulas, reglas o parámetros que se deban seguir, es un momento histórico que llevará tiempo, posiblemente mucho más que el de la misma violencia vivida, pero que al final permitirá a las nuevas generaciones contar con otros parámetros de convivencia, los de una sociedad hetérogenea que resuelve sus diferencias o conflictos de otras maneras, distintas a la violencia. Siguiendo a García Márquez (1995), se trata de

canalizar hacia la vida la inmensa energía creadora, que durante siglos hemos despilfarrado en la depredación y la violencia, y nos abra al fin la segunda oportunidad sobre la tierra que no tuvo la estirpe desgraciada del coronel Aureliano Buendía. Por el país, próspero y justo que soñamos: al alcance de los niños (p. 56).

\section{Referencias}

Agencia Colombiana para la Reincorporación y la Normalización (ARN) (2019). Disponible en http://www.reincorporacion.gov.co/es

Bocanegra, M. (2015) Arte, discapacidad y posconflicto en Colombia, Revista Eleuthera, (12), 131-140. Dor: https://doi.org/10.17151/eleu.2015.12.7 Disponible en: http://eleuthera.ucaldas.edu.co/downloads/Eleuthera12_7.pdf

Castaño, P. (2004). Reseña de "Pensando sociológicamente" de Zygmunt Bauman. Pensamiento y Cultura, (7), 155-158.

Centro Nacional de Memoria Histórica (CNMH) (2015). Una nación desplazada: informe nacional del desplazamiento forzado en Colombia, Bogotá, CNMH - UARIV.

Centro Nacional de Memoria Histórica [CNMH] (2013) Basta ya: Colombia, memorias de Guerra y Dignidad. Bogotá: Imprenta Nacional.

Comisión Histórica del Conflicto y sus Víctimas [CHCv] (2015). Contribución al entendimiento del conflicto armado en Colombia. Ediciones Desde Abajo. Disponible en: file://D:/User/Downloads/Version_final_informes_CHCV.pdf

Colciencias (1995). Informe de la Misión de Sabios. Colombia: al filo de la oportunidad. Misión Ciencia, Educación y Desarrollo. Tomo I. Bogotá: Tercer mundo editores.

Congreso de la República de Colombia (10 de junio de 2011). Ley de víctimas, por la cual se dictan medidas de atención, asistencia y reparación integral a las víctimas del conflicto armado interno y se dictan otras disposiciones [Ley 1448 de 2011]. DO: 48.096.

Duque, M.C. (2014) Reconciliación y perdón en el Postconflicto. Programa Paz a tiempo. [En línea]. Bogotá: Universidad Santo Tomás. Recuperado de: http://soda. ustadistancia.edu.co/enlinea/pazatiempo/eje3/mod6/ unidad1/Contenido_Modulo_6.pdf

Equipo Verdad Abierta, Izaguirre, A. y Rebollo, E. (2016). Víctimas, pero no por siempre. Bogotá: Ícono Editorial.

Fundación Paz y Reconciliación. (4 de enero de 2019). Procesos de Paz en Colombia. Recuperado de: https://pares.com.co/2019/01/04/procesos-de-paz-en-colombia/

González-González, F. (2014). Poder y violencia en Colombia. Bogotá, D.C.: ODECOFI, CINEP. Disponible en: https://studylib.es/doc/6502067/en-poder-y-violenciaen-colombia--el-padre

Guzmán, G., Fals-Borda, O. y Umaña, E. (2010) La Violencia en Colombia. Tomos I y II. Bogotá: Taurus.

Guzmán, D. (2012). Reparar lo irreparable. Bogotá: ONU Mujeres Colombia. 
Instituto de Estudios para el Desarrollo y la Paz, Indepaz (23 de mayo de 2019). Todos los nombres, todos los rostros: informe de derechos humanos sobre la situación de lideresas y defensores de derechos humanos en los territorios. Recuperado de: http://www.indepaz.org.co/ wp-content/uploads/2019/05/SEPARATA-DE-ACTUALIZACIO\%CC\%81N-mayo-Informe-Todas-las-voces-todos-los-rostros.-23-mayo-de-2019-ok.pdf

Jaramillo, J. (2011). La Comisión Investigadora de 1958 y la Violencia en Colombia. Universitas Humanística, (72), 37-62.

Lira, E. y Castillo, M. (1993). Trauma político y memoria social. Psicología Política, (6), 95-116.

Marín, J. J. (2011). Las comisiones de estudio sobre la violencia en Colombia. La "voz crítica" de uno de sus protagonistas (Entrevista con el historiador Gonzalo Sánchez). Análisis político, 24(73), 159-168.

Martín-Baró, I. (1988) La Violencia Política y la Guerra como causas del trauma psicosocial en el Salvador, Revista de Psicología de El Salvador, 28, 123-141.

Martín-Baró, I. (1990). Psicología social de la guerra: trauma y terapia. San Salvador: UCA Editores.

Melo, J. O. (2017). Historia mínima de Colombia. Madrid: Turnes Publicaciones. DoI: https://doi.org/10.2307/j. ctvlnhm21
Pécaut, D. (2013) La experiencia de la violencia: los desafíos del relato y la memoria. Medellín: La carreta Editores.

Poder Legislativo, Colombia (junio de 2016) Acuerdo Final para la Terminación del Conflicto y la Construcción de una Paz Estable y Duradera. Recuperado de: https:// www.refworld.org.es/docid/5a8744d54.html

Rodríguez, A. y Gaviria, M. (2014). Cuando Gana la Vida: voces de sobrevivientes de Minas antipersonal. Handicap International.

Santos, J. M (2019). La batalla por la paz: el largo camino para acabar el conflicto con la guerrilla más antigua del mundo. Bogotá: editorial Planeta.

Sontag, S. (2013) Ante el dolor de los demás, Barcelona: Santillana Ediciones.

Todorov, T. (2007). Frente al Límite. México: Siglo xxi Editores.

Unidad de Víctimas. (2019). Registro único de víctimas RUv. Colombia. Disponible en https://www.unidadvictimas.gov.co/es/registro-unico-de-victimas-ruv/37394

Uribe, A. (2009) Perfiles del mal en la historia de Colombia. Bogotá: Universidad Nacional de Colombia.

Uribe, M.V. (2004) Antropología de la inhumanidad. Bogotá: Editorial Norma.

Vásquez, M. D. R. (2007). La Iglesia y la violencia bipartidista en Colombia (1946-1953). Anuario de Historia de la Iglesia, 16, 309-334. 
